\title{
The reputation driven interplay of relationships between clients and auditors in an auditor selection process: A multilevel network approach
}

\author{
Slobodan Kacanski ${ }^{1}$ \\ RoskildeUniversity, Denmark
}

\begin{abstract}
A bstract: This study investigates the reputation-based interplay between auditor selection and interlocking directorships from a multilevel network perspective. The aim of this article is to explore how and under what conditions reputation influences patterns of social selection processes in an assurance service context. To empirically determine the impact of reputation on establishing relational ties, this study applies exponential random graph models (ERGMs) for multilevel networks. The case study was carried out in the Danish field of mandatory audits, and findings here make a valuable contribution to the literature on auditor selection. A total of 774 annual reports were collected from 145 - 165 Danish public listed companies, and the relational data of companies was assembled, as comprised of the members of supervisory boards and partners who signed audit reports during the five-year period from 2010 to 2014. In this study, mechanisms for auditor selection were controlled by mechanisms for interlocking directorships in order to obtain a broader picture of the conditions under which board members have tendencies to select reputable auditors. The findings suggest that reputation has a significant impact on both observed processes, however, results reveal that reputation has a compensatory nature, as it drives both mechanisms of social selection but never simultaneously.
\end{abstract}

K eywords: reputation, board of directors, interlock directorship, network, ERGMs

${ }^{1}$ Corresponding author: Department for Social Sciences and Business, Roskilde University; Universitetsvej 1, 4000 Roskilde; tel. (+45) 529011 04; email address: kacanski@ruc.dk 
The reputation driven interplay of relationships between clients and auditors in an auditor selection process: A multilevel network approach

\section{J EL classification: M42}

\section{Introduction}

There are two mechanisms that drive customer demands: (1) experience (Granovetter, 1973; Davis \& Robins, 2004; Powell, 1990; Podolny, 2001), and (2) reputation. In today's auditing, it is argued that reputation plays a role in setting up market structure (OECD, 2009).

Brazel and Bradford (2011) argued that before the Sarbanes-Oxley (SOX) era, external auditors were entitled to select and dismiss their clients. However, after the announcement of the SOX, when clients became able to select which auditor to use, many questions were raised in relation to the factors and reasons that clients consider when selecting or changing their auditors (Beattie \& Fearnley, 1998; Magri \& Baldacchino, 2004; Woo \& Koh, 2001). Although, the literature in this academic field at first claimed that audit fees were the main driver influencing the selection of auditors, Beattie and Fearnley (1998) argued that fees are only the most frequently cited reason. In fact, clients who change auditors are less likely to consider economical factors (Beattie \& Feamley, 1998), but Magri and Baldacchino (2004) found that the availability of auditors and a dient's perception of their behavioral characteristics were the most important factors in the selection of an auditor. The selection and change of an auditor might have negative consequences for companies, such as to their public image (Neveling, 2006) or stock price (Asthana et al., 2010). The literature has reported that client might expect to gain better reputation if they select reputable auditor (Magri \& Baldacchino, 2004). The literature has only initiated the question of reputation and the role it might have on auditor sel ection, however, and no study yet examined the significance of reputation on a client's choice.

The literature on the structure of supervisory boards (Palmer et al., 1986) and strategies for interlocking directorships has emphasized that boards are responsible for auditor selection (PwC, 2012). Board structures and interlocking directorships (Mizruchi, 1996) have been of a special interest to researchers ever since the concepts were first seen in the US economy. By definition, "interlocking" involves the participation of a single director in a supervisory board of at least two companies at the time (Mizruchi, 1996). Studies have showed that the existence of interlocks is an integral part of company strategies and goals, such as: capital allocation (Mizruchi \& Stearns, 1988; Pfeffer, 1972), business control (Allen, 1978, 1974; Stokman et al., 1985; Zeitlin, 1974), the formation of interdependencies between companies (Pfeffer \& Salanc, 1978) and upper class cohesion (Pal mer, 1983; Useem, 1982; Zeitlin, 1974), however, Galaskiewicz et al. (1985) hypothesized that increasing prestige might be an alternative strategy to 
interlocking, arguing that companies select other companies that are better perceived.

Both streams of the literature have suggested that reputation might impact both selection mechanisms. Thus, regarding the assumptions that (1) reputation, as a social perception, might both be positive and negative (Brewer et al., 2002), and (2) companies that share a board member are likely to select the same audit firm (Davison et al., 1984), this paper argues that reputation has a significant impact on both selection processes (auditor and company with which to interlock), and that those processes are mutual ly interdependent By adopting a network methodology, this paper aims to provide an examination of how reputations are distributed across the network of inter-company and auditor-client relational ties. The network approach used here offers a unique opportunity to challenge the previous two literature streams, and therefore, the analysis is centered on the following research question: How does reputation affect the social selection process in the auditing context?

The paper is structured as follows. First, I present the research area, motivations behind the investigation and the research question in the introduction of the paper. Second, the background outlines relevant literature on the topic, including the theoretical background of the study. The methodology, data collection and method are then described. I present the findings of the analysis, followed by a discussion involving the theoretical background of the study. Finally, the conclusions explicitly answer the research question and delineate the limitations of the study, and an agenda is offered for future research.

\section{L iterature review, hypotheses development and theoretical background}

\subsection{R eputation in the contexts of auditing and inter locking directorships}

Recent research has emphasized the importance of reputation through the role it has in determining social relations across different social contexts. Various studies have depl oyed their own definitions of the concept, but for this study I readapt the definition developed by Fombrun (1996:72) who defined reputation as 'a perceptual representation of a social actor's past action and future prospects that describes its overall appeal'. Reputation is recognized as an intangible asset (Goldberg et al., 2003) which is a reflection of a person's or social group's perception.

Researchers studying corporative contexts were interested in various aspects of reputation (Barnett et al., 2006). In the business world, reputation is predetermined as a fundamental resource for achieving competitive advantages, which ensure the 
sustai nability of the business entity (Barney, 1991; Deephouse, 2000; Martínez \& Olmedo, 2010). Several studies have showed that self-perception might provide insights into someone's own reputation, but the concept recognizes that reputation emerges in the eyes of others (Stuart et al., 1999; Turban \& Cable, 2003). Miles and Covin (2002) stated that reputation is fragile commodity as a result of perception, and is difficult to achieve but easily lost.

Unlike prestige which is subjective and can be only a positive value (Maner \& Case, 2016; Henrich \& Gil-White, 2001; Norredam \& Album, 2007), reputation is an objective social concept that can be both positive and negative (Brewer et al., 2002: 27-8; Henrich \& Gil-White, 2001; Highhouse et al., 2009: 1482), and the value of it emerges from the summative perception of an entire community et al. 2010). This study will thus focus on reputation due to its objective nature, and since the collected data and the scale of the observed network did not enable subjective perceptions to be either observed or analyzed.

Various studies in auditing have discussed the implications of reputation for auditing firms and auditors. Linthicum et al. (2010) argued that auditor reputation is important for clients, and asserted that clients tend to compensate for the diminished reputation level of auditors by investing in corporate social responsibility in order to stabilize or enhance their own social position. Magri and Baldacchino (2004) assumed that clients tend to overpay in order to have their annual reports audited by reputable auditors, which implies that, in both cases clients are likely to pay more, but might select either reputable or disreputable auditors according to the incentives. Magri and Baldacchino (2004) assumed that a client's selection of a reputable auditor might also enhance their reputation, and compensate for the negative consequences of the change. Kanagaretnam et al. (2010) reported that an auditor's reputation and their earnings management are negatively correlated. This is because reputable auditors tend not to risk their own reputation, and they refuse bribes offered by clients to report favorable opinions. Sucher \& al. (1999) argued that audit firm reputation is primarily based on technical and functional properties, where the size of the firm is what indicates the quality of service (DeAngelo, 1981; Salehi \& Kangarlouei, 2010). Aronmwan et al. (2013) reported that the reputation of an audit firm might affect the corporate image of a client, which implies that the selection of a Big 4 firm might enhance the credibility of a client's financial statements, compared to that of a non-Big 4 firm (Simunic \& Stein, 1987; Francis \& Wilson, 1988). The first stream of literature therefore shows that audit firm reputation might be of importance to clients, since clients might perceive selecting reputable auditors as increasing their own social standing.

On the other hand, the literature on reputation-driven interlocks has argued that increased reputation is a sign of improved legitimacy and trustworthiness (Parkhe, 1993). Board members perceive that the formation of an interlock with reputable 
companies might have a positive impact on their own reputation as well. Boards might therefore employ a cooptation strategy for business alliance formation in order to gain legitimacy (Gu \& Lu, 2014), which might further be manifested in tendencies to increase proximity to those that are generally perceived as reputable (Gu \& Lu, 2014). Podol ny (2001) suggested that status is relationally reflexive and an awareness of its sensitivity urges actors to carefully select the other social actors, because low-status holders might lower the status of those hol ding a better position. This corresponds to the mechanism of opportunities and needs, and suggests that cooptation is less likely to occur if differences in perceived levels of reputation or other attributes are apparent between focal actors (Galaskiewicz et al., 1985; Gu \& Lu, 2014). Overall, studies have reveal ed that, in the context of corporate governance, interlocks are likely to emerge between companies that hold similar socially perceived reputations.

To the author's knowledge, there were only two studies that have examined the contexts of auditor selection and interlocking directorships. In an Australian context, Davison et al. (1984) found that links betwen companies audited by the same audit firm can, to a considerable extent, be explained by links between those same companies when they have a director in common. On the other hand, by focusing on an experience-based demand mechanism, Johansen and Pettersson (2013) found that interlocks in Denmark have a strong impact on the selection of auditors and audit fees. The gap found in previously proposed framework urges bridging the seemingly disparate bodies of theory by discussing the question of how two reputation-driven demands are mutual ly negotiated through mechanisms of interlocking directorships and auditor selection.

To tackle some of the limitations of the previous literature, and theorize about the mechanism of auditor sel ection through mechanisms of interlocking directorships, I define two hypotheses that will betested by conducting network studies.
$\mathrm{H1}$ : Reputation plays an important rolein driving the demand mechanisms of auditor selection and interlocking directorships. $\mathrm{H} 2$ : Clients tend to sel ect reputable auditors when they want to compensate for a lack of homphily at the level of interlocks.

\subsection{Theoretical perspectives}

This subsection presents the main theoretical background where the aim is to frame the space and conditions within which results of the study are discussed. Use of social network analysis, as a research method, is theoretically insufficient and the engagement of the respective theory that will provide generalizations of findings is crucial (Robins, 2015: 216). I outtine the theory which, I believe, will provide a meaningful framework for the discussion of empirical results. 
I justify the selection of a theoretical background on the following assumption. Market demands that evolve under the condition of egocentric uncertainties, when social actors tend to select other actors who hold higher social status, occurs only when selectors are unaware of the quality that selected actor provides (Podolny, 2001). DeAngelo (1981) argued that the audit market is just like that, because clients are unable to gather insight into the quality of the audit service In general, social actors might enhance their legitimacy in the eyes of the others by forming relationships with those that are reputable (Baum \& Oliver, 1992), selecting those of higher rather than lower status (Podolny, 1993). In such a way, they are being influenced by previous quality uncertainties to enter the zone of "conspicuous consumption" (Podolny, 2001), which they use to demonstrate their belonging to the group of those that are reputable. Consequently, it appears that social actors tend to connect and identify themsel ves with others as they use the status of others to increase recognition within their own environment. According to Zuckerman (1999), patterns of relationships formed by firms are not only relevant for the exchange of, for example, information or services, but for those patterns might have an impact on the perception that third parties have of social actors and their engagement in relationships with others. Taking that into account, in addition to auditor selection companies establishing interlocks, it is questionable how patterns of relational ties emerge at the network level.

Correspondingly, the theoretical framework of this study is given by a combination of elements that have been outlined by reputation and identity theory. Despite notable similarities in conceptualizations of reputation across various theoretical standpoints, theorists have occupied different perspectives and grounded their theories on different assumptions, allowing researchers to select the most appropriate one (Musum \& Tovey, 2011; Burke et al., 2011; Craik, 2009). Central to this study is the viewpoint of Craik (2009) who argued that the concept of reputation al ways operates within networks of social relations. His assertion was that reputation is not located on or in a person, but it is a dispersed phenomenon found in the beliefs and assertions of groups. It is therefore a part of the social environment that is uniquely referenced to a specific social actor. In general, any discussions related to reputation are often vague in terms of who it is that holds beliefs and assertions, but the subjects of the reputation are clearly specifiable, finite in number, and unique to each social actor. More specifically, Craik (2009) devel oped a network-based model of reputation, and asserted that it has systematic implications for the diversity of disciplines, including the social network analysis. In this theory, he suggested that a change in reputation network might emerge as an initiative that is triggered by social actors. Such a premise implies that reputation might recreate structures of social relationships, where a particular actor's incentives determine the distribution of network dynamics. Craik's (2009) theory conceptualizes reputation network as a structure of relational ties where social incentives, which might be different in nature and contextually independent, 
determine and restructure the network configuration. In this study, reputation is understood as a variable that is independent from network ties as it gives an opportunity to observe the change of the network structure over time, which is the main unit of the analysis, and context specific.

To reflect the incentives of social actors, reputation theory requires the support of an additional theory that will enable the proper discussion of findings. According to Fombrun (1996) five factors are critical for establishing reputation at the corporate level, and one of these is identity, which Fombrun interprets as seeing an organization as genuine. To integrate the notion of identity into the network study of reputation in terms of the dynamic nature of relationships between social actors, I assume that it is legitimate to inspect how social actor incentives could be linked to particular social identity scenarios, and which scenarios could be particularly ascribed to incentives for social identification by observing the characteristics of network configurations. Bringing this closer, the use of this theory will enable a determination of whether reputation might be asserted to serve as a mechanism or a tool for boosting social identification.

I use theory developed by Tajfel and Turner (1979) who grounded their main propositions on theories of intergroup behavior and intra-group morale, cohesiveness and cooptation. Three principles are fundamental for actor entities seeking social identity: (1) individual s al ways strive for positive social identity; (2) which is, to a large extent, based on favorable comparison; (3) but in the event it becomes perceived as unsatisfactory, social actors might switch to others that are perceived as more positively distinct. Tajfel and Turner (1979) define three strategies for enhancing identity: (1) individual mobility - as a strategy for dissociating from the erstwhile group and joining the other, (2) social creativity - to seek alternative criteria for comparison when no change occurs, and (3) social competition - as an aggressive scenario of seeking positive distinctiveness through direct competition of the out-group.

To conclude, if it is accepted that reputation has a given value that drives network structure, and that incentives for acquiring reputation are changeable and conditioned on relationships, and that establishing relationships with reputable actors might be used as a tool for boosting social position by identifying through that relationship, it could be argued that the network theory of reputation and identity theory might give a solid basis for the interpretation of findings.

\section{M ethodology}

\subsection{The Danish regulation and corporate context related to auditor selection}

The Danish corporate governance system of publicly listed companies involves two tiers, and comprises a supervisory board, which appoints an executive board. 
Depending on which type of top tier is empl oyed, the Danish corporate governance system might be categorized as either a 'classical' or 'modified' two-tier system, and accordingly, representatives sitting on those boards have different responsibilities. In Denmark, public listed companies follow a classic two-tier structure, and the modified system is also applied to some extent. Disregarding the previous categorization, representatives of the top tier boards have different responsibilities, such as determining business principles and strategies, ensuring proper organization, deciding on risk policies and supervising the performance of the executive management.

In addition to responsibilities, Article 41 from the 2006 amendment of the European Directive on statutory audit prescribes an obligation for the board to make a decision of appointment of the auditor, which, once made, should be announced at the annual general meeting (AGM). In practice, supervisory board members make the final decision on auditor appointment, but their decision might to some extent be moderated by the recommendation of an audit committee, if present. Only a small sample of companies has separately appointed audit committees, however, which, if present, usually consist of members of the supervisory boards. If an audit committee is not appointed, the board of directors must be explicit in announcing that they take the overall responsibilities that are in jurisdiction of the audit committee.

For the purpose of this study I take into consideration only representatives of supervisory boards, since they are fully liable for appointing an external auditor. I do not distinguish the formal positions of members on boards, and assume that each member might equally effect a decision about the appointment of the auditor. The top tier in the corporate governance structure was selected for this study, as their representatives might simultaneously occupy multiple positions on the boards of different companies, and by chairing at multiple tables might equally impact multiple auditor sel ection processes, by choosing the same auditor.

Some features of regulation have affected the research design. From 1930 all listed companies in Denmark were obligated to appoint two audit firms, but joint audits were abandoned in 2005. In Denmark, information on the audit partners that signed the audit report is transparent, and it is not uncommon that two partners sign off on the same audit report. This has enabled me to identify the audit partners that were responsible for the audits and relate that information to a particular company, instead of the information of the auditing firm Usually, up to two partners put their signatures on the report, but there are some examples where two audit firms collaborated on a single engagement, which resulted in four partner signatures on a single audit report. 


\subsection{Data collection}

The data here covers the five year period from 2010 to 2014. I selected that period because there were no changes in regulations for mandatory audits in Denmark, and the period was uninterrupted by mergers, which were, by all means, very specific to the Danish audit context, since two huge mergers took place in 2008 (PwC) and in 2014 (KPMG), in Denmark.

In order to investigate interdependencies among the relationships between two types of social relations, companies sharing board members and their relationships with auditors in the context of auditor selection, I collected and extracted relational data from publically available annual reports for the purpose of this study. Relationships were extracted from the reports that were taken from the sample of Danish companies listed at Nasdaq OMX Copenhagen in each year of the observed period. A complete list of companies representing the sample was taken from a monthly report on equity trading from the $31^{\text {st }}$ of December in each of the five consecutive years. All relevant annual reports were either collected from the official websites of companies, or via the online registry of Danish business entities, Virk.dk, which contains information and documents, such as annual reports, for all business entities in Denmark. Investor relationships departments delivered missing data via email.

For this study 774 annual reports were collected in total, respectively 165, 162, 153,149 and 145 for each year of observation from 2010 to 2014. As the number of collected annual reports corresponded to the size of the sample of business entities included in observations, a condition of completeness for network studies was fulfilled. The sample includes both financial and non-financial organizations, and a total of 191 unique business entities were included in the study. The structure of business entities slighty varied over the period, however, since some companies were listed and delisted during the time, which suggests that the inventory was not entirely stable. In total, information about 1761 board members was extracted and the data included 297 audit partners who signed off on the reports of 191 company, which were affiliated to, in total, 17 audit firms.

Reputation data was collected from two separate sources. At first, information related to company reputation scores was extracted from the annual RepTrak ${ }^{\circledR}$ reports issued by the Danish branch of the Reputation Institute in each respective year. The institute provides quantitative measures of company reputation scores that are appraised based on the following seven categories: product/service, innovation, workplace, governance, citizenship, leadership and performance. The quantification of each of these categories was used as an independent measure whose sum gives the final score reported in percent, and refers to both private and public companies. For the purpose of this study, only reputation scores related to relevant companies were extracted, but since the observed sample did not match 
the list of companies being appraised by RI, the entities omitted were assumed to be disreputable. This further supported the assumption that prestige, which is a highly subjective perception, could not be used in this study. On the other hand, in relation to the reputation of audit firms and auditors, I followed the arguments of Kanagaretnam et al. (2010) and McLennan and Park (2016), who primarily used a two-type classification of audit firms as a reputation proxy, Big 4 and non-Big 4 (Fuerman \& Kraten, 2008; Aronmwan et al., 2013). This classification implied that the first group was reputable, and the latter were disreputable audit firms. Following that classification, and since this study deals with individual auditors rather than audit firms, I used auditor affiliations to proxy their individual reputation scores.

To put the data in a form appropriate for statistical modeling, raw relational data was first extracted to a unique spreadsheet from which relevant information was selected and converted to a .csv format readable by Visone, which is a network visualization tool. In addition to visualizations it also provides an opportunity to export relational data from a visual form to an adjacency matrix in .txt format that is further readable by MPNet (Wang et al., 2013), which is the software used here for statistical modeling. The extracted data finally produced estimations for five statistical models that will be discussed below, from which theoretical inferences weredrawn.

\subsection{M ethod}

To extract findings from this case study it was crucial to select the appropriate method for the analysis. The aim of this study was to identify patterns of network configurations assembled from relationships between companies sharing directors and auditors with regard to reputation-based auditor selection. This case was selected to enable a better understanding of whether and how immaterial commodities govern social selection processes. With that focus, this study finds that social network analysis (SNA) is the most appropriate method for conducting an examination of the collected data, as it enables the identification of the structure and evolution of network patterns assembled around mutually interdependent social relationships.

According to Wassermann and Faust (1994: 11) social network analysis is a quantitative-based method, which emerged as a combination of empirical, theoretical and mathematical aspects of social relations, when different disciplines struggled to make sense of their relational data. There are different techniques in the research methodology of social network analysis, but technique selection is primarily driven by the nature of the observed network (one-mode, multiple, bi partite, multilevel, etc.) and boundaries predetermined by the researcher (Robins, 2015). So far, SNA has been widely used as a research method in fields such as 
sociology, psychology, business, organization, politics, etc. An advantage of this method is that it provides estimations on network statistics with regard to observed network patterns (configurations) and attributes, and the statistical results it produces represent estimations of how particular network configurations or observed attributes play a role in structuring the entire network. A particular advantage of this method is that it enables simultaneous estimation to be conducted over a range of selected network parameters, through which it is possible to identify interdependencies between individual observations. Importantly, the method does not conflict with the classical statistical methods, but rather adds to previous statistical approaches.

This study aims to simultaneously observe social processes existing between relationships among homogeneous (company to company) and heterogeneous (company to auditor) social actors. This network is thus most appropriately categorized as multilevel, since two types of relationships were observed between two types of actors. Although the network is configured as multilevel, relationships between homogeneous social actors have not been observed at both levels, so auditor-to-auditor relationships were excluded as no reputation effect was expected at the bottomlevel of the network.

Figure 1: B oard interlocks and auditors - simplified visualization of the observed network

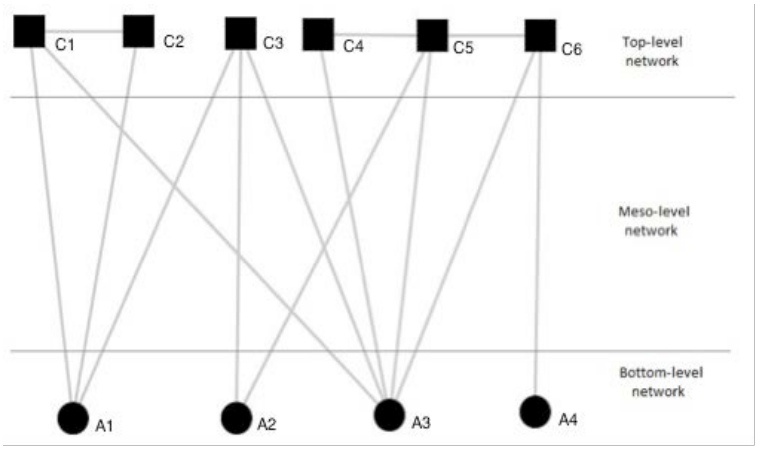

Note: In Figure 1 squares represent companies (C) and circles represent auditors (A) together with their respective IDs. The figure here is a simplification of the multilevel network analyzed in this paper. This study considers only top (company-tocompany / interlock) and meso-level (company-to-auditor / mandatory audit) networks. Ties at both network levels are non-directional.

This study used recently developed exponential random graph models (ERGMs) for multilevel networks (Wang et al., 2013), which is a culting-edge statistical model to produce the network statistics. The model will project the structure of network ties by using information on relationships between observed actors, supporting them with theoretical ly selected attributes to serve as predictors of ties. ERGM works as a pattern-recognition device, which was originally developed for examination of one-mode networks by Frank and Strauss (1986) and Wasserman and Pattison (1996). ERGMs are concerned with explaining the patterns of ties in a social network (Lusher et al., 2013), and assume that stochastic processes generate 
relational ties between them, which fits the theoretical conceptualization of reputation. ERGMs assume that ties in networks emerge through two distinctive processes: (1) network self-organization - presence or absence of other ties, and (2) social selection - due to the attributes of social actor. This study focuses on the latter, and specifically on the association of exogenous attributes and propensity of tie formation (Lusher et al., 2013). One major example of such a process is the 'homophily' effect where ties tend to emerge between actors holding the same attribute (McPherson et al., 2001). ERGMs hold the premise that the overall network structure is comprised of small mechanisms that lead to tie formation processes. This study considers network statistics in order to capture those network patterns whose emergence is not likely to occur at random The network parameters observed in this study fully correspond to theoretically conditioned relational mechanisms. Final ly, I estimate network statistics by integrating both top and meso-level parameters into the single model, and develop network estimations for each observed year. These estimations will enable an understanding of the drivers of local structural patterns, while their occurrence is conditioned on the likelihood of observing the overall network (Robins et al., 2007).

\section{Analysis of results}

\subsection{Sample description}

Table 1 provides a summary of the descriptive statistics for the observed network models, and Table 3 reports the model estimations for network structural parameters and selected social actor attributes. It captures the most important properties of the two-mode interlock and auditor selection multilevel network for each of five observed years in order to identify the essence that is crucial for understanding the models. All networks are structurally different in regard to the number of companies (145 - 165), total numbers of board members (898 - 970) and auditors (161 - 189). Nevertheless, the presented ratios differ across observed network structures.

The densities of each network and in each year are below $1 \%(0.73 \%-0.86 \%)$, which signifies low-density networks. That might be a consequence of regulation which determines the number mandatory engagements per year and number of partners per engagement, which could be assembled between auditors and companies. Across the observed years the average number of supervisory board members was below $7(\mathrm{~m}=6.54-6.86$ / SD $=2.52$ - 2.73), which in comparison with the size of supervisory boards in other countries, such as the US, may be considered relatively small. The average number of interlocks per board ranges from 1.11 - 1.16 (SD = $0.42-0.44)$, which implies the stability of an interlock network across the time, and rarely more than one director that interlocks at one 
board of directors. Finally, on average $1.82-1.91$ (SD $=0.38-0.54$ ) audit partners were engaged per client per year, while each auditor had 1.63 - 1,75 (SD =1.08 1.17) audit engagements per year.

T able 1. Sample description

\begin{tabular}{|c|c|c|c|c|c|}
\hline & 2010 & 2011 & 2012 & 2013 & 2014 \\
\hline $\begin{array}{l}\text { Number of companies } \\
\text { (clients) }\end{array}$ & 165 & 162 & 153 & 149 & 145 \\
\hline $\begin{array}{c}\text { Number of board } \\
\text { members } \\
\text { (Individuals / with } \\
\text { overlaps) }\end{array}$ & $\begin{array}{c}970 \\
(1086)\end{array}$ & 963 (1074) & 922 (1026) & 898 (1000) & 899 (994) \\
\hline $\begin{array}{l}\text { Number of audit firms } \\
\text { Number of auditors }\end{array}$ & 13 & 12 & 10 & 10 & 10 \\
\hline $\begin{array}{c}\text { (Individuals / with } \\
\text { overlaps) }\end{array}$ & 189 (315) & 189 (310) & $167(290)$ & 161 (282) & $163(265)$ \\
\hline $\begin{array}{c}\text { R atio auditors to audit } \\
\text { firms } \\
\text { Average number of }\end{array}$ & $\begin{array}{l}14.54 \\
(24.23)\end{array}$ & $15.75(25.83)$ & 16.7 (29) & $16.1(28.2)$ & $16.3(26.5)$ \\
\hline $\begin{array}{c}\text { members per board of } \\
\text { directors (supervisory } \\
\text { board) }\end{array}$ & $\begin{array}{c}m=6.54 \\
S D=2.62\end{array}$ & $\begin{array}{c}m=6.63 \\
S D=2.52\end{array}$ & $\begin{array}{l}m=6.71 \\
S D=2.61\end{array}$ & $\begin{array}{l}m=6.71 \\
S D=2.73\end{array}$ & $\begin{array}{l}m=6.86 \\
S D=2.61\end{array}$ \\
\hline $\begin{array}{l}\text { Average number of } \\
\text { interlocks per board of } \\
\text { directors (supervisory } \\
\text { board) }\end{array}$ & $\begin{array}{l}m=1.12 \\
S D=0.42\end{array}$ & $\begin{array}{l}m=1.16 \\
S D=0.43\end{array}$ & $\begin{array}{l}m=1.11 \\
S D=0.44\end{array}$ & $\begin{array}{l}m=1.11 \\
S D=0.44\end{array}$ & $\begin{array}{l}m=1.11 \\
S D=0.43\end{array}$ \\
\hline $\begin{array}{l}\text { Average number of } \\
\text { audit partners per } \\
\text { company (client) }\end{array}$ & $\begin{array}{l}m=1.91 \\
S D=0.54\end{array}$ & $\begin{array}{l}m=1.91 \\
S D=0.46\end{array}$ & $\begin{array}{l}m=1.89 \\
S D=0.42\end{array}$ & $\begin{array}{l}m=1.89 \\
S D=0.48\end{array}$ & $\begin{array}{c}m=1.82 \\
S D=0.38\end{array}$ \\
\hline $\begin{array}{l}\text { Average number of } \\
\text { audit engagements per } \\
\text { auditor }\end{array}$ & $\begin{array}{l}m=1.67 \\
S D=1.13\end{array}$ & $\begin{array}{l}m=1.64 \\
S D=1.17\end{array}$ & $\begin{array}{l}m=1.73 \\
S D=1.23\end{array}$ & $\begin{array}{l}m=1.75 \\
S D=1.08\end{array}$ & $\begin{array}{l}m=1.63 \\
S D=1.17\end{array}$ \\
\hline $\begin{array}{l}\text { Total density of two- } \\
\text { mode multilevel } \\
\text { interaction network }\end{array}$ & $0.73 \%$ & $0.73 \%$ & $0.84 \%$ & $0.86 \%$ & $0.82 \%$ \\
\hline
\end{tabular}

\subsection{M odel estimations}

Table 3 provides estimations of the five respective models for each observed year, which are organized into three horizontal sections. The first and second sections represent statistics related to network structural effects. Specifically, they give estimations of parameters related to ties between companies sharing di rectors (onemode) and companies selecting auditors (two-mode). The third section outlines estimations related to variables (reputation, net income and company size), which are integrated into the model together with network structural parameters that are theoretically determined. Attributes are further distinguished in two subsections in order to enable the transparency of both one-mode and two-mode network attribute effects. All models are discussed to provide an understanding of the interdependence between network structures and observed attributes. 
The reputation driven interplay of relationships between clients and auditors in an auditor selection process: A multilevel network approach

Overall, model estimations reveal that observed network is characterized by the presence or the absence of a certain number of patterns. Significant patterns are those that are likely to occur more or less often than could be expected by chance. The presence and significance of attribute effects indicates the extent to which a particular attribute contributes to the network formation process. Despite the fact that findings are partial ly inconsistent across observations, a trend in regard to how the social selection process unfolds is identifiable across the network statistics. Table 2 presents the network patterns that were included in model estimations, which are derived based on previously delineated theoretical assumptions.

Table 2. Network patterns included in the models

\begin{tabular}{|c|c|c|}
\hline Visualization & $\begin{array}{l}\text { Parameter } \\
\text { (M PNet) }\end{array}$ & Interpretation \\
\hline & $\begin{array}{l}\text { Edge- 1-mode } \\
\text { network edge }\end{array}$ & $\begin{array}{l}\text { Tie between two companies sharing a } \\
\text { board member (Control effect) }\end{array}$ \\
\hline & $\begin{array}{l}\text { ATA - 1-mode } \\
\text { network closure } \\
\text { effect }\end{array}$ & $\begin{array}{l}\text { Companies forming closure effect } \\
\text { through ties of interlocks }\end{array}$ \\
\hline & $\begin{array}{l}\text { XEdge- 2-mode } \\
\text { network edge }\end{array}$ & $\begin{array}{l}\text { Tie between company and auditor } \\
\text { (Control effect) }\end{array}$ \\
\hline & $\begin{array}{l}\text { XACB - 2-mode } \\
\text { network clustering } \\
\text { effect }\end{array}$ & $\begin{array}{l}\text { Interlock has no impact on selection } \\
\text { of the same auditor }\end{array}$ \\
\hline & $\begin{array}{c}\text { ATXAX - 2-mode } \\
\text { network closure } \\
\text { effect }\end{array}$ & $\begin{array}{c}\text { Interlock has an impact on selection of } \\
\text { the same auditor }\end{array}$ \\
\hline \multicolumn{3}{|l|}{ Control effects } \\
\hline & $\begin{array}{l}\text { Star2A - 1-mode } \\
\text { network }\end{array}$ & $\begin{array}{l}\text { Companies tend to sharea board } \\
\text { member between two companies } \\
\text { (Markov model effect) }\end{array}$ \\
\hline & $\begin{array}{l}\text { A2PA - 1-mode } \\
\text { network }\end{array}$ & $\begin{array}{l}\text { Companies forming clustering effect } \\
\text { through ties of interlocks }\end{array}$ \\
\hline & $\begin{array}{l}\text { XStar3B - 2-mode } \\
\text { network }\end{array}$ & $\begin{array}{l}\text { Auditor tends to audit three clients } \\
\text { (Markov model effect) }\end{array}$ \\
\hline & $\begin{array}{l}\text { XASB - 2-mode } \\
\text { network }\end{array}$ & Auditor popularity effect \\
\hline
\end{tabular}

Vol. 16, No. 3 


\begin{tabular}{ccc}
\hline Visualization & $\begin{array}{c}\text { Parameter } \\
\text { (M PNet) }\end{array}$ & Interpretation \\
\hline & $\begin{array}{c}\text { XASA - 2-mode } \\
\text { network }\end{array}$ & Company selecting more auditors \\
\hline
\end{tabular}

In the following, I provide with an overview of the results for each separate network, together with an overview of the entire period of observation to enable a dynamic approach.

\subsection{Structuring principles of shared directorship network}

The results of network parameter estimations related to the top-level network indicate that companies are likely to have a shared board member(s) in the structure of the supervisory boards (board of directors). In network terms, this implies that relational ties are likely to become established between companies through interlocking directorships. More specifically, the positive and significant statistics of the observed network parameter shows that the interlocking directorship network is rather structured according to a more complex rule than a singletie observation might reveal.

The focal network structuring parameter shows that relational ties between companies tend to create a strong closure effect, which is both positive and significant in all five models across the entire period. The significant parameter value indicates that an interlock network is characterized by the presence of small regions where two companies that share at last one board member are likely to share their board members with the same other companies, if more than one other interlock is established with more than one additional company. This implies that the emergence of interlocks with the same companies might be di rectly ascribed to an al ready existing interlock between two focal companies, where the interlock al so affects the emergence of other interlocks.

The closure effect is an alternating triangle like form network configuration where the number of triangles, interlocks with the same other companies, is rather flexible, and does not specify the direction, origin, which particular individual board member represents the interlock, or whether the common actor mediates multiple interlocks. It al so reveals the path that board members tend to take when they structure a network of interlocks. The results here show that a closure effect is the main structuring principle, which might create a condition for the direct information flow between boards comprising the network. It is also possible to assume that, due to the information flow, companies that are structuring the closure might be engaged with similar decisions related to other possible relationships, such as auditor selection. 
In three out of five observations, models were controlled by the Markov two-star effect in order to achieve model convergence, which represents the approach to network statistics at the common point. Good convergence is indicated by the tratios being close to zero. In all three cases negative and significant statistics were produced, and those results showed that companies, in general, are not likely to have exactly two interlock ties with other companies, which corresponds to the information on the average number of interlocks per board of directors (supervisory board) presented in Table 1. Those results correspond with the social circuit network parameter (closure), where the significance of a complex network structure requires more than two interlock ties to emerge from a single entity in order to forma particular configuration.

The second part of the analysis is driven by the assumption that social selection processes within social networks are conditioned by similarities in attributes that actors in the network hold. In this step I inspect the extent to which different attributes drive the homophily effect in relation to interlock emergence, taking into account a condition of attribute interdependence. For this purpose I integrated company size, total earnings (net income) and reputation scores for each company as main variables. The attributes of company size and net income are categorized as continuous, while reputation is predetermined as a binary variable. The aim of these attributes is to examine how the strength of similarities in particular characteristics determines the emergence of relational ties. The incorporation of all three attributes to network structural parameters allowed an examination of whether, and if so which, previously selected attributes surpass the others in terms of significance, and therefore might be described as the model's most influential attributeregarding tie emergence.

The results in all five estimations showed that similarity in company size and financial results have no significant effect on predetermining the interlock emergence when reputation is integrated in the model as a separate variable. The results indicate that interlocks tend not to emerge between companies that are similar in number of employees, which were used here as a proxy for company size, nor at the level of the bottom line result. Although the observed models demonstrated mainly positive network statistics, all previous attributes were insignificant, and thus the size and incomebased homophily effects on interlock emergence tend to occur at random 
Table 3. R esults of the exponential random graph models for selected years

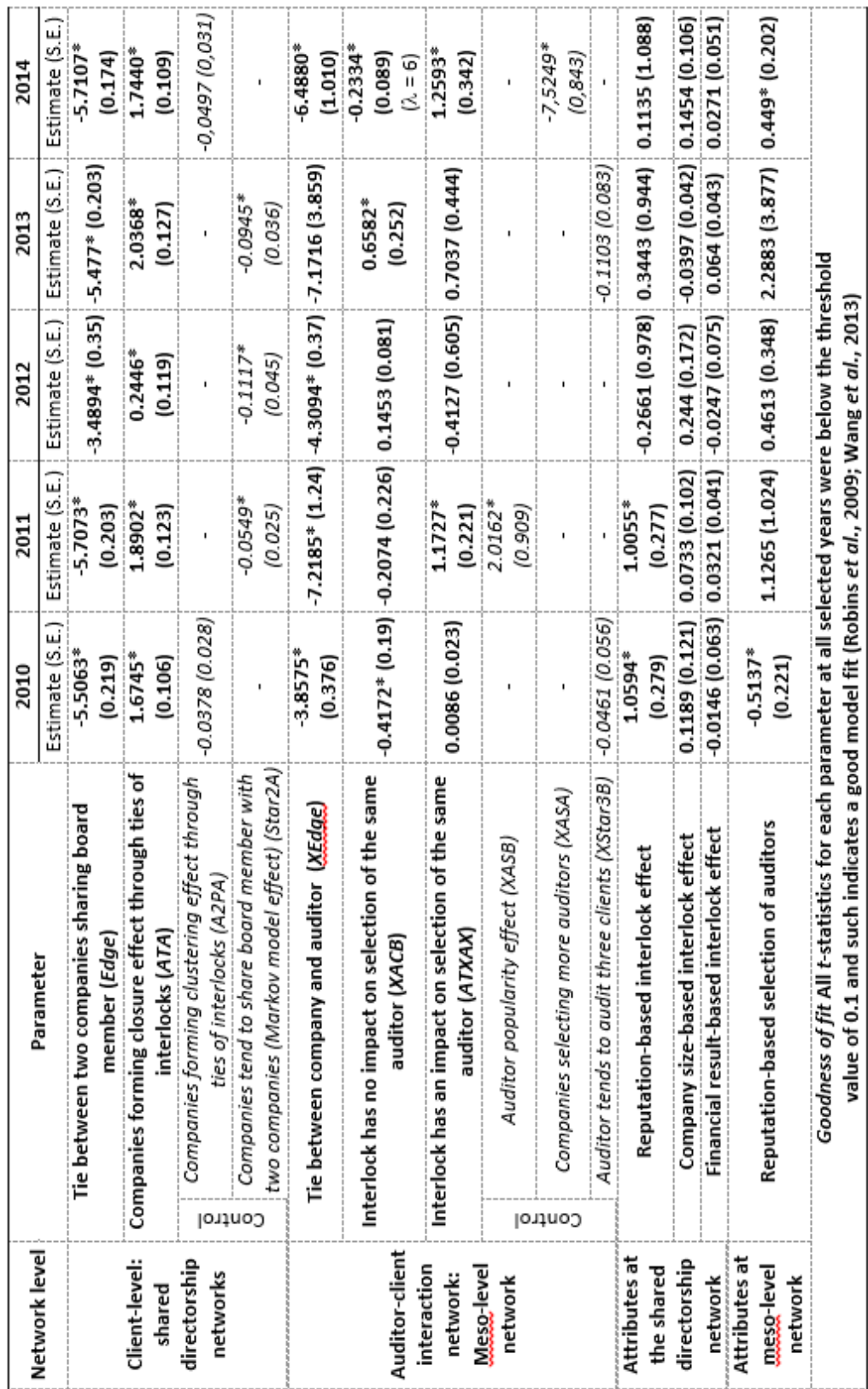

Notes: All reported coefficients are unstandardized. Z score was used only to convert client size and net-income values into a narrower span relative to their original values. Statistically significant effects were captured at or beyond 0.05 level. The value of $\lambda=2$ has been used here as an initial value as it has been proven to be reasonable for many ERGMs estimations, however higher values, as indicated $(\lambda=6)$, contribute convergence in the case of highly skewed degree distributions (Koskinen \& Daraganova, 2013; Robins et al., 2007). Omitted parameters at both network levels were excluded either because the model convergence could be reached without them or could not be, if otherwise 
The reputation driven interplay of relationships between clients and auditors in an auditor selection process: A multilevel network approach

\subsection{The impact of company attributes on one-mode network social selection process}

Mode estimations, on the other hand, show that reputation scores might affect interlock emergence. Based on the estimations, in the first two models (2010 and 2011) the reputation-based homophily effect is both positive and significant, and reputation effect was either positive or negative, but insignificant in the following three models. Comparing those results to the network structuring parameters it could be inferred that a strong positive closure effect is present between reputable companies in years when reputation effect was significant, but as the closure effect is durable over time because decisions for establishing alliances are strategic, the diminished significance of reputation statistics might not be a sign of the reduced importance of reputation effect on alliance emergence, but rather a sign of diminished levels of reputation scores between companies making closures, which further disturbs the effect of reputation-based homophily. Potentially reduced reputation scores between members of highly closured network areas might suggest the irrelevance of reputation for interlock emergence. However, this might require additional inspection of whether and how, on the other levels of the network, reputation effect might potential ly be compromised or regai ned.

\subsection{Structuring principles of auditor selection network}

Continuing with presentation of estimated models, in one part of the observation it was estimated whether the selection of auditor can be determined by the presence of interlocks, and in particular, the selection of the same auditor. The effect of an interlock on auditor selection was examined by testing the two opposite network structuring principles, through which it was possible to identify the prevalent significance In particular, whether the presence of an interlock has an impact on auditor selection or not. These two effects differ in regard to the presence or absence of a tie between companies (clients) in relation to the same auditor selection. The results of simultaneous inspection of the top-level and meso-level network showed that across the entire observed period, apart from 2012, interlocks had a positive and significant effect on selection of the same auditor. Although the 2012 model produced insignificant statistics, the positive parameter value shows that the tendency is present, but the insignificant statistics might be a result of changes in the structure of companies being listed at particular time. Overall, the results here imply that interlocks have a positive and significant impact on auditor selection, and this might be a result of previously discussed closure effect which implies that the transmission of information between boards of directors is established through interlocks.

Additional network structuring principles were included within several models to enable network convergence. They included auditor popularity effect, auditor 
tendencies to select three clients (which is a Markov 3-star effect) and company tendencies to select more auditors. Each of these network parameters was insignificant except the last, which was significant and negative, which was expected since regulatory requirements prevent companies from selecting an arbitrary number of auditors.

\subsection{The impact of auditor reputation on client choice}

Finaly, to encompass the entire model estimations and reflect on the previously defined hypotheses, I report the following findings related to reputation in earlier discussions about findings of the observed models. The findings here prompt inconsistent but rather interesting reflections on whether and how reputation plays a role in social selection processes.

Network statistics show that the impact of an auditor's reputation on client selection varies across models over the observed period. The first of five models shows negative and significant statistics for the reputation-driven selection of auditors, implying that the companies were less likely to select auditors with positive reputation scores, or who are considered reputable. In the fol lowing three models, the reputation statistics started gathering positive values, but were still insignificant, however, in the very last model the effect of reputation on auditor selection became positive and significant. Regardless of the fact that the model statistics gave cross-sectional estimations of network observations, it is clearly seen that there are tendencies for clients in this case to be prone to altering incentives for selecting reputable auditors.

Overall, the effect of the changed and increased significance of auditor reputation scores on the client sel ection process could be directly related to the emergence of a reputation-based interlock. Considering two reputation based social selection processes, homophily for interlock emergence and the selection of an auditor, it is possible to identify an interplay in which a single attribute type is produced between two network levels, and finally to identify cross-level reflections on relational tie emergence. In models where the reputation-based interlock effect was positive and significant, the effect of reputation-based sel ection of the auditor was negative and significant or either insignificant. This could be interpreted as meaning that companies might not be interested in selecting reputable auditors when they have established ties with reputable companies through interlocks, or in other words, when interlock cluster representatives hold similar reputation levels. The finding here supports the assumption that in the latter models, when the reputation effect between companies became insignificant, reputation-based effect on the selection of auditor was the opposite, positive and significant It might seem that the ease of auditor reselection and a change towards those that are reputable might be used as the tool to compensate for the lack of reputation effect at the 
company level network, because interlock alliance formation is relatively more durable and hard to disrupt.

It is possi ble to confirm that reputation, in general, has an important and significant role in social selection processes within actors of the same, and between actors of different, types. More specifically, auditor reputation plays an important role in the selection process of clients, but only when diminished reputation scores disturb the reputation effect at the interlock level. Acknowl edging this, it could be argued that both hypotheses, $\mathrm{H} 1$ and $\mathrm{H} 2$, have been proved.

\subsection{G oodness of fit analyses}

As recommended by Robins et al. (2009) and Wang et al. (2013), each model presented has been tested for goodness of fit. T-values have been estimated for all available network configurations, and estimates for observed network parameters were below 0.1, and below 2 in absolute values for all the other network configurations, suggesting reliable results (A ppendix 1).

\section{Discussion}

In agreement with two streams of literature that an immaterial commodity such as reputation might have a significant effect on social selection processes in the contexts of interlocking directorships (Galaskiewicz et al., 1985) and auditor selection (Magri \& Baldacchino, 2004), the study here examined whether and how reputation mutually negotiates between the two contexts. Although the literature only hypothesized an impact of reputation on social tie emergence, a separate examination of those two contexts would result in limited understanding of the reputation effect in an audit context Arguing that reputation might negotiate between two social selection processes, reputation-driven tension prompted an investigation of how such interdependence drives the interplay of social selection processes. To jointly examine the effect of reputation on relation emergence, I utilized exponential random graph models (Wang et al., 2013) to quantify the interdependence and identify the mutual impact of two separate, but arguably contingent, reputation-driven tendencies. This was done through an examination of relational ties and the network configurations that they have formed across five separate models that were captured across the observed period. The results of the analysis suggest that reputation has a significant effect on the emergence of both interlocks and auditor selection, but the emergence of relationships is causal and reputation effect is compensatory. 
Initially, this study confirmed that interlocks impact auditor selection (Davison et al., 1984; J ohansen \& Pettersson, 2013), but also that Danish interlocks have a strong tendency to form complex, closurelike network configurations, which might enable information flow and managing decisions across the alliances. In respect to other studies on strategies for establishing interlocking directorships (Mizruchi \& Stearns, 1988; Stokman et al., 1985; Pfeffer \& Salanc, 1978; Useem, 1982) and reasons for auditor selection and change (Beattie \& Fearnley, 1995; Magri \& Bal dacchino, 2004; Woo \& Koh, 2001), the findings showed that, in both contexts, relationships tend to either exist between those that are reputable, or to emerge towards those that are reputable. The social selection process is characteristic of network studies, as ties between homogeneous actors exist and emerge through the homophily effect, and the results here demonstrate that no material elements drove the effect of emergence, while the reputation, as an immaterial element, did. Not all models showed that reputation had a significant effect on interlock emergence, however, the results here challenged the argument of Gu and Lu (2014) who claimed that in a lack of homophily it is hard to establish proximity with the others social actors. Their argument is questionable due to the durability of interlock ties, which implies that the actors involved in social networks might experience changes in attributes over time. In this regard, the diminished significance of reputation, which is a result of changed reputation scores between companies forming closures, does not result in redistribution of ties representing interlocking directorships towards those that were re-evaluated as reputable, but rather keeps them stable despite the unequal distribution of reputation scores.

The duration of interlock alliances and investigation of homophily effects to determine the relevance of reputation by inspecting only the network of interlocks, would bring concern about whether reputation has durability in terms of significance, or is rather random since it depends on current eval uation scores. An inspection of how a level of auditor reputation becomes relevant to companies when closure effects do not sustain homophily effect between those that assemble closure becomes a crucial part of the investigation. Results reveal ed the existence of an alternative mechanism that companies undergo in order to compensate for an imbalance at the homogeneous actor level of the network. This mechanism of compensation brought complexity to strategies for establishing ties, in this case, with auditors. This indicated that a deficit of reputation-based homophily drives changes of relationships between companies and auditors, particularly those that are also carriers of the focal attribute, but at the other network level. Divergences in durations of interlock-based alliances and client engagement with auditors enables companies to use auditor reputation as a temporary mechanism to compensate for the current lack of reputation-based homophily. This study further extends the argument of Gu and Lu (2014) and Galaskiewicz \& al. (1985), as it touches upon how companies deal with the issue of unequal distribution of 
reputation in order to protect their social position from being perceived as either disreputable, or being connected with those that are disreputable.

This study also gives an indication that social actors might find that their relationships with other social actors may contribute to the social perception of themselves, as they tend to navigate through relationships in order to eliminate the negative effects that more durable relationships (interlocks) might bring. This offers a rationale for discussing the results of reputation networks from the perspective of identity theory, as social environments are comprised of stratified social groups, and social actors might use such mechanisms to signify their identification through others, which might enhance their social standing. Reflecting on identity theory, it is notable that board members, in fact, use reputation as a strategy for identification, since they tend to establish relationships with those that are reputable if they are perceived as reputable, as well. Put differently, companies establish relationships with heterogeneous social actors to compensate for an imbalance in reputation between the homogeneous group, which they use as a tool for re-identification.

Giving empirical context to the theoretical categorization of social processes in alignment with identity theory, the case here reveals that two strategies are characteristic of this context. In fact, two processes resemble the strategies of social creativity and individual mobility (Tajfe \& Turner, 1979) as they give complementary perspectives on scenarios that social actors tend to pursue at the multilevel network level. The strategy of social creativity enables network participants to seek positive distinctiveness through an alternation of criteria for comparison, while the mobility strategy enables them to make movements towards higher-status groups. More specifically, companies, while still holding interlocks, tend to seek an alternative source of comparison in order to enhance their own social standing. This means that the social creativity strategy enables companies (clients) to locate the source of reputation to altemative groups of social actors, because the ability to manipulate relational ties enables them to react promptly to reputation imbalance by switching to reputable auditors. This means that, at the level of homogeneous networks, companies use social creativity strategy to distinguish themselves from the group, and there is no change in interlock structure, however, at the heterogeneous level, companies tend to switch to reputable auditors by using this as a mechanism to improve previous standing in the group to which they belong.

\section{Conclusion}

The paper here addressed the research question: How does reputation impact the social selection process in an auditing context? The objective of this study was to 
consider two assumptions on reputation in the context of the interlock-based selection of auditors, to investigate whether and under what conditions reputation creates interplay between two social selection processes. The investigation was conducted by application of exponential random graph models, and the findings of the study have extended what we know from the literature about the impact of interlocking directorships on auditor selection.

The results of the study outline that, within the interlocking directorship network, companies tend to form closurelike strategic network configurations between reputable companies. More importantly, when the level of reputation becomes unequal among the members assembling closures, companies tend to use the opportunity to establish relationships with reputable auditors, which previously had not been considered. The study revealed that actual relationships and the reputation of those with whom companies form relationships, play significant roles in how social actors imagine themselves to be perceived by others. In other words, the reputation-based social selection model produces dynamics in the structure of the multilevel network ties between homogeneous and heterogeneous social actors. It is thus possible to conclude that companies tend to use auditor reputation as a tool to compensate for a lack of bal ance at the level of reputation, experienced through those with who they interlock, and enhance their perception in the eyes of others.

By pointing out how reputation reveals the interplay of relationships between interlocks and auditors, this study contributes to the existing literature on auditor selection and change. In fact, it responds to the call for research into the demand mechanism of auditor selection based on reputation (J ohansen \& Pettersson, 2013), and therefore adopts a relational perspective to estimating network statistics by involving two types of social actors that are interrelated by two types of relational ties, which were used here as the unit of the analysis. In this regard, this study investigated the interdependencies between several observed multilevel network configurations over five consecutive years within an auditing context, where individual mobility and social creativity together characterized patterns of the evolution of the reputation network. Finally, this study used identity theory to discuss the results, which led to a discussion of how we might understand the observed network patterns, and simultaneously how these two theoretical perspectives could be used to discuss the results of multilevel networks structures.

Nevertheless, this study is not free of limitations. On the one hand, even though the sample comprised the entire population of companies listed on the Nasdaq OMX, subsidiary Copenhagen, at the particular time of each consecutive year observed, the results are only country specific and a wider geographical extent of the analysis would be welcome. On the other hand, this study provided insights into network patterns and network tendencies over time, and it would be worth investigating the perceptions of board members, both those that interlock and those that do not, and auditors from both Big/non-Big 4 companies, and intersect their arguments against 
the previous results. Finally, this study was limited to the extent that reputation re gain was not observed, but which could be overcome through the integration of a larger number of models.

\section{R eferences}

Allen, M. P. (1974) "The structure of interorganizational elite cooptation: Interlocking corporate directorates", American Sociological Review, vol. 39(3): 393-406

Allen, M. P. (1978) "Economic interest groups and the corporate elite structure", Social Science Quarterly, vol. 58(4): 597-615

Aronmwan, J. E., Oghenekome, T. A., \& Chijioke, O. M. (2013) "Audit Firm Reputation and Audit Quality", European Journal of Business and Management, vol. 5(7): 66-75

Asthana, S. C., Balsam, S., \& Krishnan, J. (2010) "Corporate Governance, Audit Firm Reputation, Auditor Switches, and Client Stock Price Reactions: The Andersen Experience", International J ournal of Auditing, vol. 14(3): 274-293

Autore, D. M., Billingsley, R. S., \& Schneller, M. I. (2009) "Information uncertainty and auditor reputation", Journal of Banking and Finance, vol. 33(2): 183-192

Barnett, M. L., J ermier, J. M., \& Lafferty, B. A. (2006) “Corporate reputation: The definitional landscape", Corporate Reputation Review, vol. 9(1): 26-38

Baum J. \& Oliver, C. (1992) "Institutional embeddedness and the dynamics of organizational populations", American Sociological Review, vol. 57(4): 540-559

Beattie, V. \& Fearnley, S. (1995) "The importance of audit firm characteristics and the drivers of auditor change in UK listed companies", Accounting and Business Research, vol. 25(100): 227-239

Beattie, V. \& Fearnley, S. (1998) "Audit market competition: Auditor changes and the impact of tendering", The British Accounting Review, vol. 30(3): 261-289

Brewer, D. J., Gates, S. M., \& Goldman, C. A. (2002) "In Pursuit of Prestige: Strategy and Competition in US Higher Education", Unpublished manuscript

Brazel, J. F., \& Bradford, M. (2011) "Shedding New Light on Auditor Switching", Strategic Finance, vol. 92(7): 49-53

Burke, R., Martin, G., \& Cooper, C. (2011) Corporate Reputation: Managing Opportunities and Threats, Gower Publishing Limited

Craik, K. (2009) Reputation: A Network Interpretation, Oxford University Press

Davison, A. G., Stening, B. W., \& Wai, W. T. (1984) "Auditor concentration and the impact of interlocking directorates", J ournal of Accounting Research, vol. 22(1): 313-317 
Davis, G. F. \& Robbins, G. (2004) "Nothing but net? Networks and status in corporate governance", In K. K. Cetina \&A. Preda (Eds.) The sociology of financial markets, Oxford University Press, pp. 290-311

DeAngelo, L. E. (1981) "Auditor size and audit quality", J ournal of Accounting and Economics, vol. 3(3): 183-199

Francis, J. R., \& Wilson, E. R. (1988) "Auditor changes: A joint test of theory relating to agency costs and auditor differentiation", Accounting Review, 63(4): 663-680

Frank, O., \& Strauss, D. (1986) "Markov graphs", Journal of the American Statistical Association, vol. 81(395): 832-842

Frendy, \& Hu, D. (2014) “Japanese stock market reaction to announcements of news affecting auditors' reputation: The case of the Olympus fraud", J ournal of Contemporary Accounting and Economics, vol. 10(3): 206-224

Fombrin, C. (1996) Reputation: Realizing value from the corporate image, Harward Business School Press

Gal askiewicz, J., Wasserman, S., Rauschenback, B., Bielefedd, W., \& Mullaney, P. (1985) "The affect of corporate power, social status, and market position on corporate interlocks in a regional network", Social Forces, vol. 64(2): 403-431

Goldberg, A. I., Cohen, G., \& Fiegenbaum, A. (2003) “Reputation building: Small business strategies for successful venture development", J ournal of Small Business Management, vol. 41(2): 168-186

Granovetter, M. (1985) "Economic action and social structure: The problem of embeddedness", American J ournal of Sociology, vol. 91: 481-510

Gu, Q., \& Lu, X. (2014) "Unraveling the mechanisms of reputation and alliance formation: a study of venture capital syndication in China", Academy of Management J ournal, vol. 35(2): 739-750

Henrich, J., \& Gil-White, F. J. (2001) "The evolution of prestige: Freely conferred deference as a mechanism for enhancing the benefits of cultural transmission", Evolution and Human Behavior, vol. 22(3): 165-196

Highhouse, S., Brooks, M. E., \& Gregarus, G. (2009) "An organizational impression management perspective on the formation of corporate reputations", J ournal of Management, vol. 35(6): 1481-1493

J ohansen, T. R., \& Pettersson, K. (2013) "The impact of board interlocks on auditor choice and audit fees", Corporate Governance (Oxford), vol. 21(3): 287-310

Kanagaretnam, K., Lim, C. Y., \& Lobo, G. J. (2010) "Auditor reputation and earnings management: International evidence from the banking industry", J ournal of Banking and Finance, vol. 34(10): 2318-2327

Linthicum, C., Reitenga, A. L., \& Sanchez, J. M. (2010) "Social responsibility and corporate reputation: The case of the Arthur Andersen Enron audit failure", J ournal of Accounting and Public Policy, vol. 29(2): 160-176

Lopez, J., Roman, R., Agudo, I., \& Fernandez-Gago, C. (2010) "Trust management systems for wireless sensor networks: Best practices", Computer Communications, vol. 33(9): 1086-1093 
The reputation driven interplay of relationships between clients and auditors in an auditor selection process: A multilevel network approach

Lusher, D., Koskinen, J., Robins, G. (2013) Exponential RandomGraph Models Theory, Methods, and Application, Cambridge University Press

Magri, J., \& Baldacchino, P. J. (2004) "Factors contributing to auditor-change decisions in Malta", Managerial Auditing J ournal, vol. 19(7): 956-968

Maner, J. K., \& Case, C. R. (2016) "Dominance and prestige: Dual strategies for navigating social hierarchies", Advances in experimental social psychology, (1st ed.). Elsevier

Martínez, I., \& Olmedo, I. (2010) "Revisión teórica de la reputación en el entorno empresarial", Cuadernos de Economía Y Dirección de La Empresa, vol. 13(44): 59-77

Masum H., Tovey, M. (2011) The Reputation Society, How Online Opinions are Reshaping the Offline World, The MIT Press

McLennan, A., \& Park, I.-U. (2016) "The market for liars: Reputation and auditor honesty", International J ournal of Economic Theory, vol. 12(1): 49-66

McPherson, M., Smith-Lovin, L., \& Cook, J. M. (2001) "Birds of a feather: Homophily in social networks", Annual Review of Sociology, vol. 27(2001): 415-444

Miles, M. P., \& Covin, J. G. (2002) “Exploring the practice of corporate venturing: some common forms and their organizational implications", Entrepreneurship Theory and Practice, vol. 26: 21-41

Mizruchi, M. S. (1996) "What do interlocks do? An analysis, critique, and assessment of research on interlocking directorates", Annual Review of Sociology, vol. 22(1): 271-298

Mizruchi, M. S., \& Stearns, L. B. (1988) "A longitudinal study of the formation of interlocking directorates", Administrative Science Quarterly, vol. 33(2): 194-210

Neveling, N. (2006) "Changing auditors: Switch hitch", Accountancy Age, Retrieved on 18.03.2016 from http://www.accountancyage.com/aal feature/1779588/changing-auditors-switch-hitch

Norredam, M., \& Album, D. (2007) "Prestige and its significance for medical specialties and diseases", Scandinavian J ournal of Public Health, vol. 35(6): 655-661

OECD (2009) Competition and regulation in auditing and related professions, Available at www.oecd.com/competition, retrieved on 19.02.2016

Palmer, D. (1983) "Broken ties: Interlocking directorates and intercorporate coordination", Administrative Science Quarterly, vol. 28(1); 40-55

Palmer, D., Friedl and, R., \& Singh, J. V . (1986) "The ties that bind: Organizational and class bases of stability in a corporate interlock network", American Sociological Review, vol. 51(6): 781

Parkhe, A. (1993) "Strategic alliance structuring: A game theoretic and transaction cost examination of interfirm cooperation", Academy of Management J ournal, vol. 36(4): 794-829 
Pfeffer, J. (1972) "Size and composition of corporate boards of directors: The Organization and its Environment", Administrative Science Quarterly, vol. 17(2): 218-228

Pfeffer, J., \& Salanc, G. R. (1978) The external control of organizations, Book Stratford Press.

Podolny, J. M. (2001) "Networks as the pipes and prisms of the market", The American J ournal of Sociology, vol. 107(1): 33-60

Powell, W.W. (1990) "Neither Market nor Hierarchy: Network Forms of Organization", Research in Organizational Behavior, vol. 12: 295-336

PwC (2012) "How audit committee members add val ue", Audit Committee Guide, pp. 1-154

Robins, G., Pattison, P., Kalish, Y., \& Lusher, D. (2007) “An introduction to exponential random graph ( $p^{*}$ ) models for social networks", Social Networks, vol. 29(2): 173-191

Robins, G. (2015) Doing Social Network Research: Network-based Research Design for Social Scientists, Sage Publication Inc.

Salehi, M., \& Kangarlouei, S. J. (2010) "An investigation of the effect of audit quality on accrual reliability of listed companies on the Tehran Stock Exchange", Review of International Comparative Management, vol. 11(5): 940-960

Simunic, D. A., Stein, M. (1987) Product of Differentiation in Auditing: a Study of Auditor Choice in the Market for Unseasoned New Issues, Canadian certified general accountant's research foundation

Stokman, F. N., Ziegler, R., \& Scott, J. (1985) Networks of corporate power: A comparative analysis of ten countries, Polity Press

Stuart, T., Hoang, H., \& Hybels, R. (1999) “Interorganizational endorsements and the performance of entrepreneurial ventures", Administrative Science Quarterly, vol. 44(2): 315-349

Sucher, P., Moizer, P., \& Zarova, M. (1999) "The images of the Big Six audit firms in the Czech Republic", European Accounting Review, vol. 8(3): 499-521

Tajfe, H., \& Turner, J. (1979) "An Integrative Theory of Intergroup Conflict", The Social Psychology of Intergroup Conflict, CA: Brooks, Monterey, pp. 7-24

Turban, D. B., \& Cable, D. M. (2003) "Firm reputation and applicant pool characteristics", J ournal of Organizational Behavior, vol. 24(6): 733-751

Useem, M. (1982) "Classwide rationality in the politics of managers and directors of large corporations in the United States and Great Britain", Administrative Science Quarterly, vol. 27(2): 199-226

Wang, P., Robins, G., Pattison, P., \& Lazega, E. (2013) “Exponential random graph models for multilevel networks", Social Networks, vol. 35(1): 96-115

Wasserman, S., \& Pattison, P. (1996) "Logit models and logistic regressions for social networks: i. An introduction to markov graphs and p*", Psychometrica, vol. 61(3): 401-425

Wasserman, S., Katherine F. (1994) Social Network Analysis - Methods and Application, Cambridge University Press 
The reputation driven interplay of relationships between clients and auditors in an auditor selection process: A multilevel network approach

Woo, E.-S., \& Koh, H. C. (2001) "Factors associated with auditor changes: a Singapore study", Accounting and Business Research, vol. 31(2): 133-144

Zeitlin, M. (1974) "Corporate ownership and control: The large corporation and the capital ist dlass", American J ournal of Sociology, vol. 79(5): 1073-1119

Zuckermann, E. W. (1999) "The categorical imperative: Securities analysts and the illegitimacy discount", The American Journal of Sociology, vol. 104: 1398-1438 